\title{
MULTI-CRITERIA DECISION MAKING FOR SUSTAINABILITY EVALUATION IN URBAN AREAS: A CASE STUDY FOR KERMANSHAH CITY, IRAN
}

\author{
ZinATIZADEH, S. ${ }^{1}-$ AZMI, A. ${ }^{2^{*}}-$ MONAVARI, S. M. ${ }^{1}-$ SobHANARDAKANI, S. ${ }^{3}$ \\ ${ }^{I}$ Department of Environmental Science, Science and Research Branch, Islamic Azad University \\ Tehran, Iran \\ ${ }^{2}$ Department of Geography, Razi University \\ Kermanshah, Iran \\ ${ }^{3}$ Department of the Environment, College of Basic Sciences, Hamedan Branch, Islamic Azad \\ University, Hamedan, Iran \\ *Corresponding author \\ e-mail: a.azmi@razi.ac.ir; phonelfax: +98-8-33-428-3907
}

(Received $19^{\text {th }}$ Mar 2017; accepted $1^{\text {st }}$ Aug 2017)

\begin{abstract}
Sustainable development refers to interactions between different aspects of economic, social and environmental features that are designed to improve the quality of human life. The aim of this study is to evaluate urban sustainability in different urban areas of the Kermanshah city of Iran. An important city in western Iran, Kermanshah faces several social, economic and environmental problems, thus confirming the need for this research. This study was completed using multi-criteria decision making (MCDM) methods, including SAW, ELECTRE and TOPSIS. The results of these three methods indicated that different urban areas in Kermanshah city have different sustainability levels and among the six urban areas, area 4 was designated as first priority. In addition, this paper offers some necessary strategies on the issues relating to the planning and management of Kermanshah city. Furthermore, the results of three methods were compared with each other. The findings of the Friedman Test showed that there is no meaningful difference between the applied methods.
\end{abstract}

Keywords: MCDM, sustainable development, SAW, ELECTRE, TOPSIS

\section{Introduction}

Presently, over 50\% of the world's population lives in cities. Cities form the core of social, economic, and environmental development and are also the most probable places to suffer setbacks (Connelly, 2007; Oliver, 2008; Varol et al., 2010). The statistics on the urban growth rate in the world show a significant increase in the rate of $3 \%$ in 1800 to $50 \%$ in 2008. On this basis, it is expected to increase up to $60 \%$ and $70 \%$ by 2030 and 2050, respectively (Khazaei et al., 2013). These changes have an impact on economic, social, and environmental conditions and can create problems such as social injustice, inappropriate population settlements, and climate change (Rasoolimanesh et al., 2011; Hassan et al., 2015; Huang et al., 2015). In order to face the aforementioned changes, new approaches and solutions, such as sustainable development, environmental justice, modern city lifestyle, and recently, smart development have been introduced (Taghvaei, 2013; Haikio, 2014). Sustainability was introduced for the first time in 1972 at The United Nations 
Conference on the Human Environment held in Stockholm. Also, the Agenda 21 was approved in 1992 among The United Nations Conference on Environment and Development in Rio de Janeiro (Whitehead, 2003). The concept of sustainable development was advanced to solve economic, social, and environmental problems; it is one of the most important debates worldwide, one that sees collaboration from international environmental organizations as well as the United Nations (Rotmansa et al., 2000; Rasoolimanesh et al., 2011; Maleki, 2013). Today, the proposed practical plan considers 21 fundamentals that provide the three necessities of our time, the environmental preservation of water, soil and biodiversity, which our lives are dependent upon (Willis, 2006). There are many definitions of sustainable development. Sustainable development is 'a kind of development by which today's generation can achieve their basic needs without limiting the future generation's resources'. This cannot be achieved till all the factors and criteria have been defined and designed in detail (Leghaee, 1999; Berke, 2000; Jansen, 2003).

Also, the different aspects of sustainable development including, economic, social and environmental should be considered. If any aspects of sustainable development are weak, the system will be unsustainable. Urban sustainable development has the ability to develop the cities and provide the urban future generations and community's needs (Hall, 1993).

Since urban sustainable development comes from the knowledge of the conditions in urban areas, the study and review of the status of such areas is essential. In earlier research, the sustainable development level of Weifang city, of Shandong province, was studied by the AHP method. The result of this study showed that the Weifang sustainability index has been increasing in the last few years due to the environmental infrastructure improvement (Wang et al., 2012). The development of urbanization under the ecological environment restriction in the western region was done by Duan (2012). This study presents the corresponding solutions to increase the urban sustainable development quality. Different methods of multi-criteria decision making (MCDM) systems, such as SAWM, ELECTRE, TOPSIS and PROMETHEE, were used while studying the sustainability of different provinces in India (Sen et al., 2014). Evaluation of urban sustainability in 287 cities in China using TOPSIS-Entropy method has been done. Since, the level of urban sustainability in China was not high and much difference between cities exist, some strategies at urban and regional scale have been proposed (Ding et al., 2016). In another study performed by Zarrabi (2014), the social sustainability of Tehran city in Iran was assessed using factor analysis, and the level of sustainability in each urban area was defined. The same research had been done in Ilam, Iran (2009), Ahwaz, Iran (2013) by Maleki, and Orumieh, Iran (2013) by Mobaraki. Several other studies have also been conducted using MCDM methods (Viteikiene et al., 2007; Rajak et al., 2015; Zhang et al., 2016; Mokhtari Malek-Abadi et al., 2016; Liang et al., 2016; Hsueh et al., 2017 ).

These studies have been done by various methods and various indicators at different cities with different problems and different conditions. They indicate that there are many differences between areas in a city in terms of social, economic and environmental sustainability indicators and high inequality exist among different urban areas. According to the literatures, the cities have a trouble with legal authority and financial resources to deal with urban problems. These studies have also provided useful information on increasing the sustainable development level of cities and agreed that the urban development should be done by sustainable plans and good management and three 
important objectives should be considered including, social equality, economic development and environmental protection. While, community participation is a key role in promoting quality of urban sustainable environment.

As a country, Iran has consistently struggled with economic, social and environmental issues. Therefore, paying attention to sustainable development is essential for the nation's present and future. Several cities in Iran have developed in unsuitable ways, leading to different issues like pollution and chaos. This is particularly challenging on metropolises, which are usually focal points of population, trade, economy, culture, as well as pollution. Despite being one of the most important cities in western Iran, Kermanshah is highly unsustainable due to rapid population growth, high migration rate and increase in trade and economic activities, all of which lead to different problems. Even with the appropriate facilities, services are unevenly distributed among different parts of the city. This study aims to assess the sustainability of urban areas in Kermanshah by using the SAW, ELECTRE, and TOPSIS methods, as well as explore necessary policies to promote the sustainability level in the different areas.

\section{Materials and methods}

\section{The study area}

Kermanshah is located between latitudes $33^{\circ} \mathrm{N}$ and $35^{\circ} \mathrm{N}$ and longitudes $45^{\circ} \mathrm{E}$ and $47^{\circ} \mathrm{E}$. The city, comprising $1.5 \%$ of Iran's total area, is located in the west and has a shared boundary with Iraq. Kermanshah Province is limited by Kurdistan in the north, Lorestan and Ilam provinces in the south, Hamedan in the east, to the country of Iraq in the west. The city of Kermanshah is the capital of the province, with a population of 818,719 people within the area of $9564 \mathrm{~km}^{2}$ (Statistical Center of Iran, 2011). According to the population and housing census from 1966 to 2011, the population of Kermanshah city has increased from 192,072 people in 1966 to 850700 in 2011, with a positive population growth rate of $3.36 \%$. Despite fluctuations, the city's population has always exhibited a positive growth trend (Zinatizadeh, 2013; Shirazi, 2013). Kermanshah has six urban areas, which are defined in Table 1 and Figure 1.

Table 1. Specification of each area of Kermanshah city (Statistical Center of Iran, 2015)

\begin{tabular}{c|c|c}
\hline Urban areas & Population & Area (Hectare) \\
\hline Area 1 & 80689 & 1442 \\
Area 2 & 100900 & 1135 \\
Area 3 & 164254 & 1654 \\
Area 4 & 151376 & 1469 \\
Area 5 & 177408 & 1711 \\
Area 6 & 144092 & 2153 \\
\hline
\end{tabular}




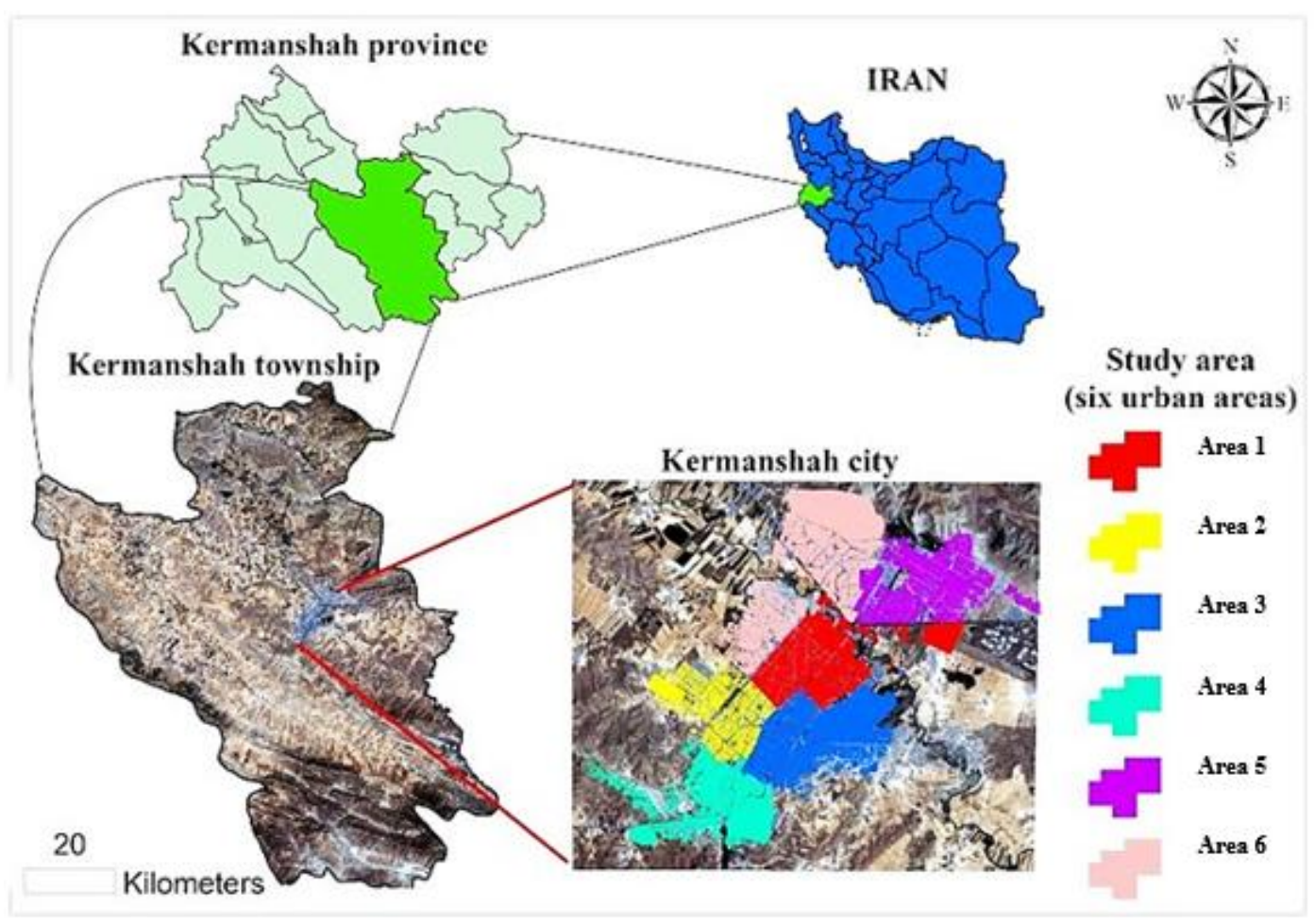

Figure 1. Location of the study area

In order to investigate sustainability of six urban areas in Kermanshah, a list of 44 indicators was prepared. The selection of indicators was based on expert opinions, conditions in Kermanshah city, access to the required data, and literature review (Mousavi, 2005; Zakerian, 2010; Jafaei, 2011; Aboubakri, 2012; Bahari, 2012; Raz-Dasht, 2012; Azani, 2013; Saraei, 2013; Saeedi Mafar, 2013; Akbari Nasab, 2014; Mokhtari, 2014; LiYin, 2011; Singh, 2009) (Table 2). The required data were gathered from different centres viz. province hall, municipality, department of environment, municipal water and wastewater company, waste management organizations, traffic and transportation organizations, renovation and reconstruction organizations, and statistics and information technology center. Additionally, Shannon's entropy method (Shannon, 1948) was used to determine the weight of indicators (Table 2).

Table 2. List of the indicators studied and their weights in Kermanshah city (Social and welfare (1-23) Economic growth (24-31) Environmental protection (32-44))

\begin{tabular}{c|c}
\hline Indicator & Weight \\
\hline (1) Population density & 0.002006 \\
(2) Literacy rate & 0.000917 \\
(3) Family size & 0.008309 \\
(4) Number of Fire station per 1000 people & 0.011512 \\
(5) Number of gas station per 1000 people & 0.031225 \\
(6) Number of toilets per 1000 people & 0.023562 \\
\hline
\end{tabular}


(7) Number of public parking per 1000 people

(8) Number of hotel per 1000 people

(9) Number of not-level intersection per 1000 people

(10) Number of central post office per 1000 people

(11) Number of park per 1000 people

(12) Number of police centers per 1000 people

(13) Number of intelligent intersection per 1000 people

(14) Number of pedestrian bridge per 1000 people

(15) Number of Database Disaster Management per 1000 people

(16) Number of hospital per 1000 people

(17) Number of clinic per 1000 people

(18) Number of drugstore per 1000 people

(19) Numb9er of university per 1000 people

(20) Number of sport centers per 1000 people

(21) Number of cultural centers per 1000 people

(22) Number of religious places per 1000 people

(23) Number of schools per 1000 people

(24)Unemployment rate

0.115307

0.109761

0.037687

0.007423

0.014057

0.028361

0.148629

0.031043

0.079185

0.095756

0.084947

0.024643

0.0869

0.001686

0.009692

0.028122

0.01927

0.199759

0.208196

0.021259

(26) Sponsorship rate

(27) Number of civil projects per 1000 people

(28) Number of shopping centers per 1000 people

0.017955

0.093252

(29) Number of markets per 1000 people

0.032902

(30) Number banks per 1000 people

0.221543

0.205136

(31) Number of recreation and tourism centers per 1000 people

0.021924

0.10955

(33) Percent of wastewater treated

(34) Percent of Population Water network coverage

(35) Percent of Population network wastewater coverage

0.000461

0.000921

0.216273

(36) Percent of source separation of solid waste

(37)Waste production per capita

0.0043

(38) Percent of Semi-mechanized collection of household waste

0.004441

(39) Number of industrial centers per 1000 people

(40) Number of database associated with environment per 1000 people

0.191567

(41) Green space per capita

0.14267

0.111328

0.053538

(42) Number of traffic jams per 1000 people

0.045457

(43) Percent of travel at peak hours

0.09757

Source: (Mousavi 2005, Zakerian 2010, Jafaei 2011, Aboubakri 2012, Bahari 2012, Raz-Dasht 2012, Azani

2013, Saraei 2013, Saeedi Mafar 2013, Akbari Nasab 2014, Mokhtari 2014, Li-Yin 2011 and Singh 2009)

Following this, the MCDM methods were used for prioritizing the urban areas. The MCDM method is a branch of operations research models which cope with decision problems that have a number of criteria (Pohekar et al., 2004). In this study, one method from each subgroup of the MCDM methods was chosen. The selective methods include Elimination and Choice Expressing Reality (ELECTRE) from the concordance sub-group, the Technique for Order Preference by Similarity to Ideal Solutions (TOPSIS) from the compromising sub-group, and Simple Additive Weighting (SAW) from the scoring subgroup of the MCDM methods. These methods are further described in the following sections. 


\section{$S A W$}

The simple additive weighting (SAW) is one of the simplest methods of the MCDM methods (Churchman et al., 1954):

Normalize the decision matrix $(N)$ :

According to the Eq. 1, the decision matrix is normalized using of linear method.

$$
n_{i j}=\frac{a_{i j}}{\operatorname{Max} a i j} \quad i=1, \ldots, m, j=1, \ldots, n
$$

Calculate the weighted normalized decision matrix $(V)$ :

The weighted normalized value $\left(v_{i j}\right)$ is obtained according to Eq. 2.

$$
V_{i j}=N_{i j} W_{j} \quad i=1, \ldots, m, \quad j=1, \ldots, n
$$

Where $w_{j}$ is the weight of the $i$ th indicator.

Select the alternative with the highest overall performance value $(A *)$ :

$$
A^{*}=\left\{A_{i} \operatorname{Max} \sum n_{i j} w_{j}\right\}
$$

\section{ELECTRE}

ELECTRE was introduced at the end of $1980^{\text {th }}$ (Roy 1968). ELECTRE Is an outranking method based on outranking relation and concordance analysis. So, this method does not necessarily results in ranking the alternatives (Velasquez et al 2013; Taha et al 2013).

Normalize the decision matrix $(N)$ :

The normalized value $\left(n_{i j}\right)$ is obtained according to the $E q .4$.

$$
n_{i j}=\frac{x_{i j}}{\left[\sum_{i=1}^{m} x_{i j}{ }^{2}\right]^{\frac{1}{2}}} \quad i=1, \ldots, m, j=1, \ldots, n
$$

Calculate the weighted normalized decision matrix (V):

The weighted normalized value $\left(v_{i j}\right)$ is obtained according to $E q .5$.

$$
V_{i j}=N_{i j} W_{j} \quad i=1, \ldots, m, \quad j=1, \ldots, n
$$

Where $w_{j}$ is the weight of the $i$ th indicator. 
Formation the concordance matrix set

$$
\begin{aligned}
S_{k, I}=\{j \mid V k j \geq V i j\}, \quad j=1, \ldots, m \\
S_{k, I}=\{j \mid V k j \leq V i j\}, \quad j=1, \ldots, m
\end{aligned}
$$

Formation the discordance matrix set

$D_{k, I}=\{j \mid V k j<V i j\}, \quad j=1, \ldots, m$

$D_{k, I}=\{j \mid V k j>V i j\}, \quad j=1, \ldots, m$

Determine of concordance matrix $\left(I_{k l}\right)$

In this stage, the concordance matrix is calculated using Eq. 6. This matrix is an $\mathrm{m}^{*} \mathrm{~m}$ matrix, which diameter of that, does not have any element. The other elements (entries) of this matrix can be calculated via summation of indicator weights that belong to concordance group.

$$
I_{k l}=\sum w_{j}, j € A_{k_{l} l}
$$

Determine of discordance matrix (NI):

In this stage, the discordance matrix is calculated using Eq. 7. This matrix is an $\mathrm{m}^{*} \mathrm{~m}$ matrix. The diameter of this matrix does not have any elements and other elements can be calculated from weighted normalized matrix according to Eq. 7 .

$$
N I_{k l}=\frac{\operatorname{Max}\left|V_{i j}-V_{l j}\right|_{, j \in D_{k, l}}}{\operatorname{Max}\left|V_{i j}-V_{l j}\right|, j \in a l l \text { indicators }}
$$

Calculate the effective concordance matrix $(H)$ :

To create this matrix, first we need to determine a threshold. If each element of matrix I, be bigger or equal to that, that factor in matrix $\mathrm{H}$, will be equal one, otherwise 0 . From the $E q .8$, the threshold for the matrix is calculated.

$$
\begin{gathered}
I=\sum_{i=1}^{m} \sum_{k=1}^{m} I_{k_{l}} / m(m-1) \\
\text { If, } I_{k i} \geq \bar{I}, \quad H_{k i}=1 \quad \text { and } \quad \text { If, } \quad I_{k i}<\bar{I}, H_{k i}=0
\end{gathered}
$$

Calculate the effective discordance matrix $(G)$ :

In this stage, the effective discordance matrix can be calculated based on the Eq. 9

$$
\overline{N I}=\sum_{i=1}^{m} \sum_{k=1}^{m} N I_{k_{I}} / m(m-1)
$$




$$
\text { If, } \quad N I_{k i} \geq \overline{N I}, \quad G_{k i}=0 \quad \text { and } \quad \text { If, } \quad N I_{k i}<\overline{N I}, \quad G_{k i}=1
$$

Determine the effective final matrix $(F)$ :

The effective final matrix can be calculated by combination of effective concordance and effective discordance matrix based on the Eq. 10 .

$$
F_{k l}=H_{k l} G_{k l}
$$

\section{TOPSIS}

TOPSIS was proposed by Hwang and Yoon in 1981. The basic concept of this method is that, the chosen alternative should have the closest distance from the ideal solution (Velasquez et al., 2013; Taha et al., 2013).

Normalize the decision matrix $(N)$ :

The normalized value $\left(n_{i j}\right)$ is obtained according to $E q .11$.

$$
n_{i j}=\frac{x_{i j}}{\left[\sum_{i=1}^{m} x_{i j}\right]^{\frac{1}{2}}} \quad i=1, \ldots, m, j=1, \ldots, n
$$

Calculate the weighted normalized decision matrix (V):

The weighted normalized value $\left(v_{i j}\right)$ is obtained according to Eq. 12 .

$$
V_{i j}=N_{i j} W_{j} \quad i=1, \ldots, m, \quad j=1, \ldots, n
$$

Where $w_{j}$ is the weight of the $i$ th indicator.

\section{Determine of positive ideal solution and negative ideal solution}

Positive ideal solution $\left(V_{j}+\right)=$ vector of the best values of each indicator $(V)$ Negative ideal solution $\left(V_{j}^{-}\right)=$vector of the worst values of each indicator $(V)$ The best values for the positive indicators are the biggest and for the negative indicators are lowest values.

Determine of Euclidean distance to positive and negative ideals:

Euclidean distance of each alternative from positive ideal $\left(d_{j}^{+}\right)$and negative ideal $\left(d_{j}^{-}\right)$ can be calculated based on Eq. 13 and 14 .

$$
d_{i}^{+}=\sqrt{\sum_{j=1}^{n}\left(V_{i j}-V_{j}^{+}\right)^{2}}, i=1,2, \ldots, m
$$




$$
d_{i}^{-}=\sqrt{\sum_{j=1}^{n}\left(V_{i j}-V_{j}^{-}\right)^{2}}, i=1,2, \ldots, m
$$

Determine the relative closeness to ideal solution $\left(C L^{*}\right)$ :

Determination of relative closeness of each alternative to an ideal solution can be calculated based on Eq. 15.

$$
C L_{i}^{*}=\frac{d_{i}^{-}}{d_{i}^{-}+d_{i}^{*}}, \quad i=1,2 \ldots, n, \quad 0 \leq C L_{i}^{*} \leq 1
$$

\section{Ranking the preference order}

Alternatives having bigger CL, are better. According to relative closeness of each alternative to an ideal solution, the ranking order of alternatives can be determined and the best alternative is selected.

\section{Results}

Based on the data obtained, the sustainability levels of six urban areas were evaluated using three methods under the MCDM, and three aspects of sustainability, including social, economic and environmental.

\section{Urban areas ranking by $S A W$}

The results obtained from SAW in three categories (social, economic, and environmental) are shown in Table 3. The best alternative selected is the one where the sum of the weighted normalized values is greater than other values.

Table 3. Results obtained from SAW method

\begin{tabular}{c|c|c|c|c|c|c|c|c}
\hline Area & $\begin{array}{c}\text { Sum of } \\
\text { environment } \\
\text { al indicators } \\
\text { values }\end{array}$ & Rank & $\begin{array}{c}\text { Sum of } \\
\text { economic } \\
\text { indicators } \\
\text { values }\end{array}$ & Rank & $\begin{array}{c}\text { Sum of social } \\
\text { indicators } \\
\text { values }\end{array}$ & Rank & $\begin{array}{c}\text { Sum of } \\
\text { indicator } \\
\text { s values }\end{array}$ & Rank \\
\hline 1 & 0.764 & 1 & 0.817 & 1 & 0.471 & 4 & 2.052 & 4 \\
2 & 0.362 & 5 & 0.695 & 2 & 0.489 & 3 & 1.555 & 3 \\
3 & 0.538 & 3 & 0.547 & 4 & 0.626 & 1 & 1.711 & 1 \\
4 & 0.602 & 2 & 0.560 & 3 & 0.600 & 2 & 1.762 & 2 \\
5 & 0.330 & 6 & 0 & 5 & 0.290 & 6 & 0.62 & 6 \\
6 & 0.368 & 4 & 0 & 5 & 0.392 & 5 & 0.76 & 5 \\
\hline
\end{tabular}

According to the results, Area 1, with a value of 2.052, is more sustainable than the others. Three areas $(4,3$, and 2) are ranked in the second, third, and fourth place, with 
values of 1.762, 1.711 and 1.555, respectively. Areas 6 and 5 are graded as fifth and sixth, with 0.76 and 0.62 , respectively.

\section{Urban areas ranking by ELECTRE}

The results of urban area ranking in three categories (social, economic, and environmental) using the ELECTRE method are shown in Tables 4, 5, and 6.

Table 4. The final dominance matrix of social indicators

\begin{tabular}{c|c|c|c|c|c|c}
\hline Final dominancy & Area 1 & Area 2 & Area 3 & Area 4 & Area 5 & Area 6 \\
\hline Area 1 & - & 0 & 0 & 0 & 1 & 1 \\
Area 2 & 0 & - & 0 & 0 & 1 & 1 \\
Area 3 & 0 & 1 & - & 0 & 1 & 1 \\
Area 4 & 0 & 1 & 0 & - & 1 & 1 \\
Area 5 & 0 & 0 & - & 0 & - & 0 \\
Area 6 & 0 & 0 & 0 & 0 & 1 & - \\
\hline
\end{tabular}

Table 5. The final dominance matrix of economic indicators

\begin{tabular}{c|c|c|c|c|c|c}
\hline $\begin{array}{c}\text { Final } \\
\text { dominancy }\end{array}$ & Area 1 & Area 2 & Area 3 & Area 4 & Area 5 & Area 6 \\
\hline Area 1 & - & 1 & 0 & 0 & 0 & 1 \\
Area 2 & 0 & - & 0 & 0 & 0 & 1 \\
Area 3 & 0 & 0 & - & 0 & 0 & 1 \\
Area 4 & 1 & 1 & 1 & - & 1 & 1 \\
Area 5 & 0 & 1 & 0 & 0 & - & 1 \\
Area 6 & 0 & 0 & 0 & 0 & 0 & - \\
\hline
\end{tabular}

Table 6. The final dominance matrix of environmental indicators

\begin{tabular}{c|c|c|c|c|c|c}
\hline Final dominancy & Area 1 & Area 2 & Area 3 & Area 4 & Area 5 & Area 6 \\
\hline Area 1 & - & 1 & 1 & 0 & 1 & 1 \\
Area 2 & 0 & - & 0 & 0 & 0 & 0 \\
Area 3 & 0 & 0 & - & 0 & 1 & 0 \\
Area 4 & 0 & 1 & 0 & - & 1 & 1 \\
Area 5 & 0 & 0 & 0 & 0 & - & 0 \\
Area 6 & 0 & 0 & 0 & 0 & 0 & - \\
\hline
\end{tabular}


Based on the results, two areas (4 and 1) have the maximum dominance, followed by areas $3,2,5$, and 6 , in that order.

\section{Urban areas ranking by TOPSIS}

For the current study, the relative closeness of each alternative to the ideal solution, in three categories (social, economic, and environmental), was calculated (Table 7).

Table 7. Relative closeness of each alternative to an ideal solution

\begin{tabular}{c|c|c|c|c}
\hline Alternatives & $\begin{array}{c}\text { Social } \\
\text { indicators }\end{array}$ & $\begin{array}{c}\text { Economic } \\
\text { indicators }\end{array}$ & $\begin{array}{c}\text { Environmental } \\
\text { indicators }\end{array}$ & $\begin{array}{c}\text { Overall closeness } \\
\text { to ideal solution }\end{array}$ \\
\hline Area 1 & 0.437 & 0.52 & 0.627 & 1.594 \\
Area 2 & 0.437 & 0.349 & 0.207 & 1.083 \\
Area 3 & 0.575 & 0.578 & 0.449 & 1.602 \\
Area 4 & 0.537 & 0.913 & 0.579 & 2.029 \\
Area 5 & 0.197 & 0.557 & 0.21 & 0.964 \\
Area 6 & 0.319 & 0.196 & 0.361 & 0.876 \\
\hline
\end{tabular}

According to the results obtained by this approach, Area 4, with a score of 2.029, is in better condition when compared to the others. Three urban areas $(3,1$, and 2$)$ are ranked second, third and fourth, with scores of 1.602, 1.594 and 1.083, respectively. The remaining areas (5 and 6), with scores of 0.964 and 0.876 scores, are ranked fifth and sixth grade, respectively.

\section{Final ranking of urban areas}

The final ranking result is based on the average of the ranks obtained from different methods (Momeni 2013). Accordingly, the final rankings of the six urban areas are shown in Table 8.

Table 8. Final ranking results

\begin{tabular}{c|c|c|c|c}
\hline \multirow{2}{*}{ Area } & \multicolumn{3}{|c|}{ MCDM methods } & \multirow{2}{*}{ Averaged rank } \\
\cline { 2 - 4 } & SAW & ELECTRE & TOPSIS & 2 \\
Area 1 & 1 & 2 & 3 & 4 \\
Area 2 & 4 & 4 & 4 & 2.6 \\
Area 3 & 3 & 3 & 2 & 1.3 \\
Area 4 & 2 & 1 & 5 & 5.3 \\
Area 5 & 6 & 6 & 6 & 5.6 \\
Area 6 & 5 & 6 & \\
\end{tabular}




\section{Discussion}

Based on this study, it is evident that different urban areas of Kermanshah city have different sustainability levels. Area 4 is listed as the first priority, followed by areas 1, 3, 2, 5 and 6, respectively. Due to the centrality of area 4, more social and public services, including health, culture, education, entertainment, sports, as well as city infrastructure and administrative buildings are located here. Area 1, which is predominantly occupied by the wealthy, is characterized by high economy; collaboration on environmental projects receives particular attention in this area (due to the location of the administrative section), and it is therefore more sustainable. In comparison, in two areas (2 and 3), the disorganized structure of streets and alleys leads to traffic problems, water and sewage-network-related accidents and difficulties in municipal waste management. Furthermore, Areas 5 and 6 are not welldeveloped due to rural migration, cheap land price and semi-rural structure. Overall, the main factors contributing to unsustainable conditions in six urban areas of Kermanshah are high unemployment rate, high solid waste production, unequal distribution of city services and infrastructures, the old structure of the city, inefficient public transportation system, lack of attention to renovation projects in older areas and social discrepancies.

Based on these limited factors, particular strategies need to be considered. These include the provision of basic services, decentralization, promoting public participation in urban planning, infrastructure establishment for proper development, building recreation and tourism centers in the city, enhancing relationship with Iraq, improving economic prosperity and reducing marginal jobs. It is further important to draw the attention of local, regional, and national planners towards creating a special economic zone in Kermanshah province, which can create various employment opportunities, and assist in the development of waste management programs and wastewater treatment plants, as well as improve public transportation, and increase green spaces across the city.

In the present study, the results from SAW, ELECTRE, and TOPSIS methods were compared using the Friedman test. Based on the sig (0/93) value, no meaningful difference was found among the methods. As seen in Table 8, areas 5 and 6, with the lowest sustainability levels are ranked similarly in all three methods. Areas 1, 3, and 4, with comparably superior sustainability levels were ranked high in all methods, while area 2 in ranked fourth in all of the methods. In the other words, all three applied methods have resulted in similar rankings.

It is probable that due to the use of a single method for weighting (Shannon's entropy), the results achieved from all three methods were similar. This suggests that in the process of alternatives prioritization, the weight of indicators is more important than the method being used (Janic et al., 2002; Zareie et al., 2011). On the other hand, the three methods applied in this study belong to compensatory MCDM methods. These refer to methods where trade-offs between the indicators are allowed (XU et al., 2001); that is, a decline in one indicator's attributes is acceptable if it is compensated by an increase in another indicator's attribute. Thus, one of the characteristics of compensatory methods is the closeness among the rankings (Ebrahimi et al., 2014). Many previous studies have shown similar results in final rankings with the use of different MCDM methods, which corresponds to the current study (Chu et al., 2007; Hoshyar et al., 2011; Momeni et al., 2011; Shirouyehzad et al., 2011; Bordbar, 2013). 
Despite the similarity between the results obtained from the three different methods, the authors propose TOPSIS as the most suitable and practical method. This selection is based on the advantages and characteristics of this method as compared to the rest. The benefits of TOPSIS are listed below - $\quad$ (Srdjevici, 2004; Falsoleiman et al., 2013; Kolios et al., 2016):

- It is capable of merging several quality and quantity indicators simultaneously.

- The method is characterized by simplicity and high speed.

- The system function is desirable and acceptable.

- The desirability of applied indicators in solving a problem can be steadily increasing (or decreasing).

- The method allows changing the primary data, and subsequently, changing the functions and outcome.

- Prioritizing in this method is done based on similarity to the ideal solution, such that the final option will be close to the ideal answer and far from the wrong answer.

- In case some of the indicators are not desirable and need to be decreased, or some others are desirable and can be increased, TOPSIS can easily calculate the ideal solution through a combination of the best values obtained from all criteria.

- TOPSIS considers the best and the worst answers simultaneously, based on closeness to the ideal solution.

- The outcomes can express the priorities quantitatively.

- Table 9 compares the specifications for the different methods.

Table 9. Comparison of characteristics of methods (SAW, ELECTRE, and TOPSIS)

\begin{tabular}{|c|c|c|c|c|}
\hline No & Feature & TOPSIS & SAW & ELECTRE \\
\hline 1 & Compared data type & $\begin{array}{c}\text { Quality and } \\
\text { quantity }\end{array}$ & $\begin{array}{c}\text { Quality and } \\
\text { quantity }\end{array}$ & $\begin{array}{c}\text { Quality and } \\
\text { quantity }\end{array}$ \\
\hline 2 & Stability of the results & + & + & + \\
\hline 3 & Simplicity & $*$ & $* * *$ & ** \\
\hline 4 & Intelligibility & $*$ & $*$ & ** \\
\hline 5 & Creditability & ** & $*$ & ** \\
\hline 6 & Flexibility & ** & * & ** \\
\hline 7 & Applicability & $*$ & $*$ & ** \\
\hline 8 & Provide better results & $*$ & * & ** \\
\hline 9 & Calculation precision & $*$ & * & ** \\
\hline 10 & Providing details & $*$ & * & ** \\
\hline 11 & Regarding the decision-maker & $*$ & * & * \\
\hline 12 & Sensibility to the weighting & **** & * & $*$ \\
\hline 13 & Ability in pair comparison & + & - & - \\
\hline 14 & $\begin{array}{l}\text { The ability to analyze a large } \\
\text { number of data }\end{array}$ & + & + & + \\
\hline 15 & $\begin{array}{l}\text { Ability to manage low quality input } \\
\text { data }\end{array}$ & + & - & - \\
\hline 16 & Computing speed & $*$ & *** & $* *$ \\
\hline
\end{tabular}

$(+=$ have,$-=$ does not have, $*=$ low, $* *=$ medium, $* * *=$ high $)$

Source :(Duckstein et al., 1982; Goicoechea et al., 1982; Hobbs, 1986; Hobbs 1992; Srdjevici, 2004; Cavallaro et al., 2005; Caterino et al., 2008; Nikolic et al., 2009; Azar et al., 2010; Achilas et al., 2011; Aruldoss et al., 2013; Amoushahi et al., 2015; Falsoleiman et al., 2013; Hatami Marbini et a. 2013; Herva et al. 2013; Mohammadi Zanjirani et al., 2013) 


\section{Conclusion}

Multi-criteria decision making methods were applied to assess the sustainability of urban areas in Kermanshah city. In this research, the authors applied the ELECTRE, TOPSIS and SAW methods for the evaluation of sustainability of urban areas using 44 indicators at three social, economic and environmental aspects. In addition, The Friedman test showed there is no significant difference between these MCDM methods. The results showed that among the six urban areas, areas 4, 1 and 3 are more sustainable than the other areas. Totally, Kermanshah city is not at good condition and is far from sustainability. Therefore, in order to achieve sustainability, especially in more deprived areas, some strategies should be done such as creating jobs, more attention to economic in undeveloped areas, cultural solution and collaboration of people in environmental issues. Equal distribution and decentralization of services and allocating funds to poor areas must be considered. The study also pointed out the advantages and disadvantages related to the application of the selected methods and the TOPSIS method was preferred due to its advantages over the other methods.

Acknowledgments. The authors are grateful to the Kermanshah Department of Environment for providing facilities to conduct and accomplish this study.

\section{REFERENCES}

[1] Aboubakri, T. (2012): The realization of urban sustainable development indicators in border areas (case study: Piranshahr city). - Urban Management 30: 222-207.

[2] Achilas, Ch., Vlachokostas, Ch., Moussiopoulos, N., Banias, G. (2011): Prioritize strategies to confront environmental deterioration in urban areas: Multi-criteria assessment of public opinion and experts views. - Cities 28: 414-423.

[3] Akbari Nasab, S. Y. (2014): Requirements and indicators for urban sustainable development. - Database for management scientific articles.

[4] Amoushahi, S., Nejadkoorki, F., Pourebrahim, Sh. (2015): An investigation on PROMETHEE and ELECTRE outranking methods in environmental decision-making of oil and petrochemical industries. - Journal of humans and the environment 33: 17-35.

[5] Aruldoss, M., Miranda Lakshmi, T., Prasanna Venkatesan, V. (2013): A Survey on Multi Criteria Decision Making Methods and Its Applications. - American Journal of Information Systems 1(1): 31-43.

[6] Azani, M. (2013): Local Sustainable Development indicators in District 13 of Isfahan. Spatial Planning Scientific-Research Journal (Geography) 3(2): 119-142.

[7] Azar, A., Vafaee, F. (2010): Rating of MADM techniques using some multi-criteria decisionmaking methods in fuzzy environment and compare it with the ranking DEA method. Journal of Behavior, Management and Progress 14: 23-38.

[8] Bahari, I. (2012): Ranking and evaluating the development of cities of Mazandaran province using factor analysis and cluster analysis. - Geography and environmental planning 23(4): 38-15.

[9] Berke, P. R., Conroy M. M. (2000): Are we planning for sustainable development? An evaluation of 30 comprehensive plans. - APA Journal 66(1): 21-28.

[10] Bordbar, Gh. (2012): Factors affecting labor productivity by MCDM techniques. - Journal of Health Administration 16. 
[11] Caterino, N., Iervolino, I., Manfredi, G., Cosenza, E. (2008): A Comparitive analysis of decision making methods for the seismic retrofit of RC buildings. - The 14th World Conference on Earthquake Engineering, October 12-17, Beijing, China.

[12] Cavallaro, F., Ciraolo L. (2005): A multi-criteria approach to evaluate wind energy plants on an Italian island. - Energy Policy 33: 234-235.

[13] Chu, M. T., Shyu, J., Tzeng, G. H., .Khosla, R. (2007): Comparison among three analytical methods for knowledge communities' group-decision analysis. - Expert Systems with Applications 33: 1011-1024.

[14] Churchman, C. W., Ackoff, R. L. (1954): an approximate measure of value. - Operations Research Society of America 2(1): 172-87.

[15] Connelly, S. (2007): Mapping sustainable development as a contested concept. - Local Environment 12(3): 259-278.

[16] Ding, L., Shao, Z., Zhang, H., Xu, C., Wu, D. (2016): A Comprehensive Evaluation of Urban Sustainable Development in China Based on the TOPSIS-Entropy Method. - Sustainability 8(8): 1-23.

[17] Duan, L. F. (2012): A study on development of urbanization in western region under the ecological environment restriction. - Advanced Materials Research 518-523: 5853-5858.

[18] Duckstein, I. (1982): Multi criterion analysis of the water allocation conflict in the Upper Rio Grande basin. - Applied Mathematics and computation 17: 245-265.

[19] Ebrahimi, M., Shojaee, A., Mohammadpoor, S. M. (2014): Multi-criteria decision-making methods sustainability ranking. - 1st National Industrial Mathematics Conference 1-8.

[20] Fal Soleiman, F., Hajipoor, M., Sadeghi, H. (2013): Comparison of different methods Multiple Attribute Decision Making AHP and TOPSIS in order to determine the areas capable of planting pistachio in Mokhtaran plain, city of Birjand by using of GIS. - Applied Research of Geographic Sciences 13(31): 133-155.

[21] Goicoechea, A. (1982): Preference to the special issue on multi-criterion decision making with engineering applications. - Applied Mathematics and Computation 54: 99-109.

[22] Hall, P. (1993): Toward sustainable cities and innovative cities for 21st century. - In Proceedings of the third conference at the world capitals, Tokyo, 22-28.

[23] Haikio, L. (2014): Institutionalization of Sustainable Development in Decision-Making and Everyday Life Practices: A Critical View on the Finnish Case. - Sustainability 6: 5639-5654.

[24] Hassan A. M, Lee, H. (2015): toward the sustainable development of urban areas: An overview of global trends in trials and policies. - Land Use Policy 48: 199-212.

[25] Hatami Marbini, A., Tavana, M., Moradi, M., Kangi, F. (2013): A fuzzy group method for safety and health assessment in hazardous waste recycling facilities. - Safety Science 51: 414-426.

[26] Herva, M., Roca, E. (2013): Review of combined approaches and multi criteria analysis for corporate environmental evaluation. - Journal of Cleaner Production 39: 355-371.

[27] Hobbs, A. (1986): an interactive integrated multi-objective optimization approach for quasiconvex utility functions. - Applied Mathematics and Computation 54: 241-257.

[28] Hobbs, A. (1992): Building public confidence in energy planning: a multi method MCDM approach to demand side planning at BC gas. - Socio- Economic Planning Science 37: 289316.

[29] Hoshyar, N., Amalnik Sadegh, M. (2011): Determination the purity using dimensional analysis, AHP and Fuzzy TOPSIS (Case Study: The company assembled fireplace gold). Journal of Industrial Management 17.

[30] Hsueh, S. L., Su, F. L. (2017): Discussion of environmental education based on the social and cultural characteristics of the community- An MCDM approach. - Applied Ecology and Environmental Research 15(2): 183-196. 
[31] Huang, L, Wu, J., Yan, L. (2015): Defining and measuring urban sustainability: a review of indicators. - Landscape Ecology 30(7): 1175-1193.

[32] Hwang, C. L, Yoon, K. (1981): Multiple Attribute Decision Making: Methods and Applications. - New York: Springer-Verlag.

[33] Jafaei, M. (2011): Evaluation of stability criteria of regions in Iran and the world to achieve urban sustainable development. - Conference on Sustainable Architecture and Urban Development, Hamedan-Iran, Sama vocational schools.

[34] Janic, M., Reggiani, A. (2002): An Application of the Multiple Criteria Decision Making (MCDM) Analysis to the Selection of a New Hub Airport. - EJTIR 2: 113-141.

[35] Jansen, L. (2003) the challenge of sustainable development. - Journal of cleaner production 1(3): 231-245.

[36] Khazaei, M., Razavian, M. T. (2013): Sustainable Urban Development (an innovative approach in the development of cities around the world). - International Research Journal of Applied and Basic Sciences: 4(6): 1543-1547.

[37] Kolios, A., Mytilinou, V., Lozano-Minguez, E., Salonitis, K. (2016): A Comparative Study of Multiple-Criteria Decision-Making Methods under Stochastic Inputs. - Energies 9: 1-21.

[38] Leghaee, H. A., Mohammad Titkanlu, H. (1999): An introduction to the concept of urban sustainable development and the role of urban planning. - Journal of Fine Arts 6: 32-43.

[39] Li-Yin, Sh. (2011): The application of urban sustainability Indicators: comparisons between various practices. - Habitat International 35: 17-29.

[40] Liang X, Zhang W, Chen L, Deng F (2016): Sustainable Urban Development Capacity Measure-A Case Study in Jiangsu Province, China. - Sustainability 8(3): 270.

[41] Maleki, S. (2009): Ranking of urban areas in terms of sustainable development indicators using factor analysis and taxonomy (Ilam). - Journal of Geography and regional development 13: 45-80.

[42] Maleki, S. (2013): Evaluation of urban sustainable development indicators with an emphasis on social, physical and utilities indicators (Case study: eight districts in Ahwaz). - Urban Planning Studies Journal 1(3): 29 -54.

[43] Mobaraki, O. (2013): Analysis of the hierarchy of Urmia on urban sustainable development indicators. - Journal of Applied Research of Geographical Sciences 13(30): 49-65.

[44] Mokhtari Malek-Abadi, R. (2014): Measurement and Evaluation of social and cultural sustainability indicators in mining towns (case study: Assaluyeh mining town). - Journal of research and urban planning 19: 91-110.

[45] Mokhtari Malek-Abadi, R, Aliakbari, E, Khosravi, B (2016): Evaluating and Assessing Sustainability of Border Cities (Case study: border city: Baneh). - International Journal of Humanities and Cultural Studies (IJHCS) 624-644.

[46] Mohammadi Zanjirani, D., Salimifard, K. H., Yoosefi Dehbidi, S. H. (2013): Check the performance of most common multi-criteria decision-making techniques with optimization approach. - Journal of the Operations Research Applications 11: 165-84.

[47] Momeni, M. (2013): Modern Topics on Operational Research. - Moallef Publications.

[48] Moment, M., Jafar Nejhad, A., Sadeghi, S. H. (2011): Optimal location of distribution centers in the marketing process using mathematical methods. - Industrial management 6.

[49] Mousavi, M. N. (2005): Factor analysis and combination of indicators in determination of factors affecting human development in the regions of Iran. - Journal of Geography and Development 55-70.

[50] Oliver, P. A. (2008): City Leadership: at the heart of the global challenge. - Global Asia 3(16): 421-432. 
[51] Pohekar, S. D., Ramachandran M. (2004): Application of multi-criteria decision making to sustainable energy planning - A review. - Renewable and Sustainable Energy Reviews 8: 365-381.

[52] Rajak, S., Vinod, S. (2015): Application of fuzzy logic for social sustainability performance evaluation: a case study of an Indian automotive component manufacturing organization. Journal of Cleaner Production 108: 1184-1192.

[53] Rasoolimanesh, S. M., Badarulzaman, N., Jaafar, M. (2011): Achievement to Sustainable Urban Development using City Development Strategies: A Comparison between Cities Alliance and the World Bank definitions. - Journal of Sustainable Development 4(5): 151166.

[54] Raz-Dasht, A. (2012): Comparison of sustainability indicators of Dehdasht small city and average urban system with an emphasis on urban sustainable development. - Journal of Environmental Planning 18: 125-142.

[55] Rotmansa, J., Asselt, M. V., Vellinga, P. (2000): an integrated planning tool for sustainable cities. - Environmental Impact Assessment Review 20: 265-276.

[56] Roy, B. (1968): Classement et choix en présence de points de vue multiples. - RAIROOperations Research-Recherche Opérationnelle 2(1): 57-75.

[57] Saeedi Mafar, S. (2013): Indicators of the healthy cities with an approach to urban sustainable development. - Eighth Congress of Architecture and Urbanism and Sustainable Development, Mashhad, Khavaran Institute of Higher Education.

[58] Saraei, M. H. (2013): Analysis and evaluation of socio - economic sustainable indicators of sustainable development in neighborhoods of Meibod historic city. - Geographical Research Quarterly 28(1):177-204.

[59] Sen, N., Ghosh, A., Saha, A., Karmaker, B. R. (2014): Sustainability status of Indian states: Application and assessment of MCDM frameworks. - IEEE 78-85.

[60] Shannon, C. E. (1948): A mathematical theory of communication. - Bell System Technical Journal 27, 379-423 \& 623-656.

[61] Shirazi, H. (2013): Economic, Social and Cultural Report of Kermanshah Province in 2011 and 2012. - First edition, Kermanshah: Taq-e Bostan Press.

[62] Shirouyehzad, H., Pourjavad, E. (2011): A MCDM Approach for Prioritizing Production Lines: A Case Study. - International Journal of Business and Management 6(10): 221-229.

[63] Singh, R. K., Murty, H. R, Gupta, S. K, Dikshit, A. K. (2009): an overview of sustainability Assessment methodologies. - Ecological Indicators 99: 189-212.

[64] Srdjevici, B. (2004): An Object Multi-Criteria Evaluation of Water Management Scenarios. Water Resources Management Journal 18: 35-54.

[65] Statistical Center of Iran (2011): Statistical Yearbook of Kermanshah province.

[66] Taghvaei, M. (2013): Urban sustainable development and the factors affecting it (Case Study: Kermanshah). - Urban Sociological Studies 3(6): 1-22.

[67] Taha, R. A., Daim, T. (2013): Multi-Criteria Applications in Renewable Energy Analysis, a Literature Review. - Research and Technology Management 2: 17-30.

[68] Varol, C., Ercoskun, O., Gurer, Y. (2010): Local participatory mechanisms and collective actions for sustainable urban development in Turkey. - Habitat International 35(1): 9-16.

[69] Velasquez, M., Hester, P. (2013) An Analysis of Multi-Criteria Decision Making Methods. International Journal of Operations Research 10(2): 56-66.

[70] Viteikiene, M, Kazimieras Zavadskas, E (2007): Evaluating the sustainability of Vilnius city residential areas. - Journal of Civil Engineering and Management 2: 149-155.

[71] Wang, L., Wang, Y. N. (2013): The Sustainability Evaluation of Weifang Urban Area. Advanced Materials Research 1285-1291. 
[72] Whitehead, M. (2003): (Re) Analyzing the Sustainable City: Nature, Urbanization and the Regulation of Socio-environmental Relations in the UK. - Urban Studies 40: 1183-1206.

[73] Willis, M. (2006): Sustainability, the Issue of our Age, and A concern for local government. - Public Management 88(7): 8-12.

[74] Xu, L., Yong, J. B. (2001): Introduction to multi-criteria decision making and the evidential reasoning approach. Manchester school of management university of Manchester institute of science and technology. - Working paper no. 0106.

[75] Zakerian, M. (2010): Urban sustainable development (Case Study: Yazd cities). Geographic Journal of Iran 25: 103-93.

[76] Zareie, B., Bagherimoghadam, N. (2011): Applying and comparing the methods of AHP, TOPSIS and ELECTRE in transition resin dry type transformers production technology. Journal of Industrial Management 1: 40-31.

[77] Zarrabi, A. (2014): A study on the social sustainability using Factor analysis case study: Tehran province. - Kuwait Chapter of Arabian Journal of Business and Management Review 3(4): 88-97.

[78] Zhang, L, Xu, Y., Yeh, C. H, Liu, Y., Zhou, D. (2016): City sustainability evaluation using multi-criteria decision making with objective weights of interdependent criteria. - Journal of Cleaner Production 131: 491-499.

[79] Zinatizadeh, A. A. (2013): Statement of Kermanshah Province Environment (SOE). Department of the Environment, Kermanshah Province. 